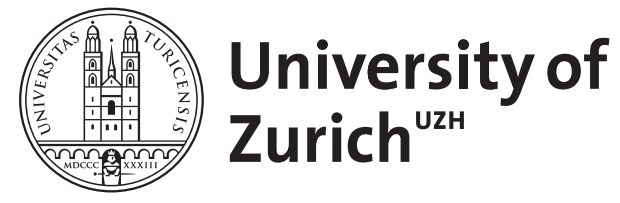

Zurich Open Repository and Archive

University of Zurich

University Library

Strickhofstrasse 39

CH-8057 Zurich

www.zora.uzh.ch

Year: 2006

\title{
Alcohol-attributable mortality and potential years of life lost in Canada
} 2001: implications for prevention and policy

Rehm, Jürgen ; Patra, J ; Popova, S

DOI: https://doi.org/10.1111/j.1360-0443.2005.01338.x

Posted at the Zurich Open Repository and Archive, University of Zurich ZORA URL: https://doi.org/10.5167/uzh-95514

Journal Article

Published Version

Originally published at:

Rehm, Jürgen; Patra, J; Popova, S (2006). Alcohol-attributable mortality and potential years of life lost in Canada 2001: implications for prevention and policy. Open Addiction Journal, 101(3):373-384.

DOI: https://doi.org/10.1111/j.1360-0443.2005.01338.x 


\title{
Alcohol-attributable mortality and potential years of life lost in Canada $200 \mathrm{I}$ : implications for prevention and policy
}

\author{
Jürgen Rehm ${ }^{1,2,3}$, Jayadeep Patra' ${ }^{1,4}$ \& Svetlana Popova ${ }^{1,5}$ \\ Centre for Addiction and Mental Health, Toronto, Canada,' Addiction Research Institute, Zurich, Switzerland, ${ }^{2}$ Department of Public Health Sciences, University \\ of Toronto, Canada, ${ }^{3}$ Department of Human Development and Applied Psychology, University of Toronto, Canada ${ }^{4}$ and Faculty of Social Work, University of \\ Toronto, Canada ${ }^{5}$
}

\begin{abstract}
Background Alcohol is one of the most important risk factors for burden of disease. Objective To estimate the number of deaths and the years of life lost attributable to alcohol for Canada 2001 using different ways to measure alcohol exposure. Methods Distribution of exposure was taken from a major national survey of Canada, the Canadian Addiction Survey, and corrected for per capita consumption from production and sales. For chronic disease, risk relations were taken from the published literature and combined with exposure to calculate age- and sex-specific alcohol-attributable fractions (AAFs). For injury, AAFs were taken directly from available statistics. Information on mortality, with cause of death coded according to the International Classification of Diseases version 10 (ICD-10) was obtained from Statistics Canada. Results For Canada in 2001, 4010 of all deaths in the group below 70 years of age were attributable to alcohol, $3132 \mathrm{in}$ men and 877 in women. This constituted $6.0 \%$ of all deaths in Canada in this age group, $7.6 \%$ for men, and 3.5\% for women. The 4010 deaths are a net figure, already taking into account the deaths prevented by moderate consumption of alcohol. Main causes of alcohol-attributable death were unintentional injuries, malignant neoplasms and digestive diseases. Ischaemic heart disease (IHD) was the biggest cause of death prevented by alcohol, with $78.7 \%$ of all alcohol-attributable prevented deaths in the age groups of 70 years and above. A total of 144143 years of life were lost prematurely in Canada in that year, 113079 years in men and 31063 years in women. Discussion Regardless of the assumptions made, alcohol is a major contributor to mortality in Canada. The impact of alcohol on social life is not confined to mortality, as other studies indicated that alcohol is linked even more strongly to disability and social harm. Alcohol-attributable harm could be substantially reduced, however, if known effective policies were introduced.
\end{abstract}

Keywords Alcohol-attributable fraction (AAF), alcohol consumption, Canada, mortality, potential years of life lost (PYLL), relative risk (RR).

Correspondence to: Jürgen Rehm, 33 Russell Street, Room 2035B, Toronto, ON M5S 2S1, Canada. E-mail: jtrehm@aol.com

Submitted 26 January 2005; initial review completed 25 April 2005; final version accepted 9 September 2005

\section{INTRODUCTION}

Alcohol is accountable for high levels of mortality, morbidity and social problems. More than 60 causes of death have been attributed to alcohol consumption (Schultz et al. 1991; Corrao et al. 1999; Rehm et al. 2003a,b). Results from studies investigating deaths attributable to alcohol vary by country and methodology (e.g. Schultz et al. 1990; English et al. 1995; Single et al. 2000; Britton et al. 2003; Centers for Disease Control \& Prevention 2004; White et al. 2004).
From a public health perspective, alcohol consumption has been shown to have adverse consequences, such as various cancers, hypertension, cirrhosis of the liver, pancreatitis, alcohol dependence, accidents and violence (English et al. 1995; Rehm et al. 2003a, 2004). On the other hand, when consumed in moderation, there was evidence of a decreased risk of ischaemic heart disease (IHD) (Doll et al. 1994; Klatsky 1994; Chick 1998; Puddey et al. 1999; Rehm et al. 2003c). In addition, according to current epidemiological standards, there has been some evidence of a protective effect of moderate consump- 
tion on ischaemic stroke, diabetes, cholethiasis or gallstones (Ashley et al. 2000). For other conditions such as peripheral vascular disease, cognitive functioning (Eckardt et al. 1998; Chick 1999), stress reduction (BaumBaicker 1985; Hauge \& Irgens-Jensen 1990), mood elevation (Pohorecky 1991; Castaneda et al. 1996, 1998) and other subjective psychosocial effects, the evidence was neither consistent nor conclusive (Ashley et al. 2000).

All-cause mortality as a summary measure thus has a $J$-shaped relationship with alcohol consumption, at least for people older than 40 years of age, when the main protective effects of alcohol on IHD become evident (English et al. 1995; Rehm \& Bondy 1998; Rehm et al. 2001a; Gmel et al. 2003a; White et al. 2004). This J-shaped relationship indicates that low to moderate drinkers have a lower mortality risk compared to the abstainers, whereas the mortality risk for highest level drinkers is higher than that of both moderate drinkers and abstainers.

The exact shape of the curve depends on the underlying mix of causes of death and the patterns of drinking (Rehm et al. 2004). Thus, the relationship between consumption and all-cause mortality cannot be used to derive precise estimates of alcohol-attributable mortality. Instead a disease-specific approach is necessary. The current paper uses such a disease-specific approach to estimate the number of deaths and potential years of life lost for Canada in 2001.

\section{METHODS}

The aim of the present study was to estimate the proportion of deaths 'caused' or 'prevented' by alcohol and premature deaths in Canada for the year 2001. In the following paragraphs, three elements necessary for this estimate are described: measurement of exposure, determination of risk relationships and attributable fractions and outcome information.

\section{Prevalence of alcohol consumption in Canada}

To measure alcohol consumption, we followed the approach of English et al. (1995) and used four drinking categories based on average volume of alcohol consumed (see Table 1 for definition). These specific drinking categories have been used, because most meta-analyses give results based on these categories (see Rehm et al. 2003a; for an overview of meta-analyses).

The prevalence data of different levels of current alcohol consumption were collected between 2003 and 2004 through the Canadian Addiction Survey (CAS) (Canadian Centre on Substance Abuse 2004). This survey was selected because it collected good alcohol consumption exposure data which are temporally closest to the mortality data. As alcohol consumption has been relatively stable in Canada over the past years, the difference of 2-

Table 1 Prevalence of alcohol consumption in Canada 2003/2004† according to age, sex and drinking category.

\begin{tabular}{|c|c|c|c|c|c|c|c|}
\hline Drinking categories & $\begin{array}{l}\text { Overall } \\
\text { (all ages) }\end{array}$ & $15-29$ years & 30-44 years & $45-59$ years & $60-69$ years & $70-79$ years & $80+$ years \\
\hline \multicolumn{8}{|c|}{ Abstention and very light drinking* } \\
\hline Female & 66.9 & 59.0 & 62.1 & 65.3 & 68.4 & 70.5 & 72.6 \\
\hline Male & 40.4 & 30.2 & 35.1 & 40.0 & 45.0 & 48.3 & 51.5 \\
\hline \multicolumn{8}{|l|}{ Drinking category I* } \\
\hline Female & 24.9 & 34.8 & 31.0 & 27.1 & 23.2 & 20.7 & 18.1 \\
\hline Male & 46.8 & 51.6 & 48.6 & 45.5 & 42.4 & 40.4 & 38.3 \\
\hline \multicolumn{8}{|c|}{ Drinking category II* } \\
\hline Female & 6.3 & 3.2 & 4.3 & 5.5 & 6.6 & 7.4 & 8.2 \\
\hline Male & 6.5 & 8.7 & 8.2 & 7.6 & 7.1 & 6.7 & 6.4 \\
\hline \multicolumn{8}{|c|}{ Drinking category III* } \\
\hline Female & 1.9 & 3.0 & 2.6 & 2.2 & 1.8 & 1.5 & 1.1 \\
\hline Male & 6.3 & 9.4 & 8.1 & 6.8 & 5.5 & 4.6 & 3.8 \\
\hline Total & 100 & 100 & 100 & 100 & 100 & 100 & 100 \\
\hline \multicolumn{3}{|l|}{ Drinking categories } & \multicolumn{2}{|c|}{ Females } & & \multicolumn{2}{|c|}{ Males } \\
\hline \multicolumn{3}{|c|}{ Abstainer or very light drinker } & \multicolumn{2}{|c|}{$0-<0.25 \mathrm{~g} /$ day } & & \multicolumn{2}{|c|}{$0-<0.25 \mathrm{~g} /$ day } \\
\hline \multicolumn{3}{|l|}{ Drinking category I } & \multicolumn{2}{|c|}{$0.25-<20 \mathrm{~g} /$ day } & & \multicolumn{2}{|c|}{$0.25-<40 \mathrm{~g} / \mathrm{day}$} \\
\hline \multicolumn{3}{|l|}{ Drinking category II } & \multicolumn{2}{|c|}{$20-<40$ g/day } & & \multicolumn{2}{|c|}{$40-<60$ g/day } \\
\hline \multicolumn{3}{|c|}{ Drinking category III } & \multicolumn{2}{|c|}{$40+$ g/day } & & \multicolumn{2}{|c|}{$60+$ g/day } \\
\hline
\end{tabular}

${ }^{\dagger}$ Average volume of alcohol consumption has been based on a smoothed quantity frequency measure derived from the Canadian Addiction Survey, corrected for per capita consumption. For further explanations of this measure please see text. *The drinking categories were based on the following definitions (see National Health and Medical Research Council, Australia 1992; English et al. 1995) 
3 years between mortality and exposure data seems to be negligible.

The CAS was based on a regionally stratified two-stage (telephone household, respondent) random sample. The survey used random-digit-dialling methods via computer assisted telephone interviewing. The sampling frame was based on an electronic inventory (Statplus) of all active telephone area codes and exchanges in Canada. Within selected households, one respondent aged 15 years or older who could complete the interview in English or French was selected according to the most recent birthday of household members. The selected individuals were interviewed by professional interviewers using a structured questionnaire. The sample was drawn randomly from the whole of Canada taking into consideration age, sex and region to avoid sample bias. This survey had a sample size of 13909 men and women, and a 47\% response rate for individuals. It was decided to use this survey despite the relatively low response rate because it had the necessary exposure measures for the intended calculations, large sample size to allow provincial calculations and closest temporal proximity to the mortality data. In addition, it has been shown that higher response rates in surveys did not essentially change the results with respect to the distribution of alcohol consumption (Gmel \& Rehm 2004). To strengthen the confidence in these data and to ensure that characteristics of CAS sample are similar to the Canadian population, this sample was weighted to correspond to the age and sex distribution of the Canadian population.

Different measures for alcohol exposure were used, including a quantity frequency (QF) measure, where usual frequency and usual quantity per drinking occasion were asked in separate questions and then combined to derive overall volume. A 7-day protocol was also used where, starting with the day before the survey, consumption of each of the past 7 days was asked (for further explanation see Gmel \& Rehm 2004). As QF is a more reliable measure to indicate individual volume (Gmel \& Rehm 2004), we used this measure for our main scenario, and the 7-day protocol as one of the sensitivity analyses. Sensitivity analyses were conducted as it has been shown clearly that method of assessment has an important impact on estimated alcohol-attributable mortality and other harm (Rehm et al. 1999).

For per capita consumption (for a definition see Rehm et al. 2003d), numbers were taken from the Global Alcohol Database (http://www3.who.int/whosis). As the CAS accounted for only $30 \%$ and $40 \%$ of the per capita consumption (including unrecorded consumption), depending on which measure was used, we scaled the two highest alcohol consumption categories of the QF upwards in our main scenario by the factor of underreporting for QF. In other words, we multiplied the age and sex-specific prevalence rates by 2.7 to reflect the true per capita consumption based on the coverage rate of $36.6 \%$ or the QF. Per capita consumption, when including unrecorded consumption, is usually considered as the best measure for overall consumption in a country (Gmel \& Rehm 2004). Of course, this measure has the disadvantage that it cannot give any indication of sex- or age-distributions of drinking (Rehm et al. 2003d).

\section{Computing alcohol-attributable deaths}

The alcohol-attributable fraction (AAF) is generally defined as the proportion of the disease in the population that will disappear if alcohol is removed (Walter 1976, 1980). Since alcohol may 'cause' or 'prevent' deaths, the AAF can be positive or negative. AAFs were assessed for different specific causes of natural and unnatural deaths by two methods:

- AAFs for chronic disease were calculated by combining exposure and relative risk estimates from meta-analyses. Relative risk here denotes the ratio of the probability of developing, in a specified period of time, a disease among those exposed to alcohol, compared with the probability of developing this disease for abstainers.

- AAFs for injuries were based on direct estimates of alcohol involvement where available for Canada (traffic accidents; fire); and for other types of injury were based on results from the America A region derived by the comparative risk analysis of the Global Burden of Disease study (Rehm et al. 2004; for details of calculation see below).

For chronic disease conditions, the AAFs were calculated from alcohol exposure prevalence proportions in Canada and the pooled relative risks for the diseases from the update of comprehensive meta-analyses. We used the most comprehensive meta-analysis for each condition, as indicated in Table 2 (see Rehm et al. 2003a for an overview). 'Most comprehensive' was determined by the meta-analysis with the greatest number of unique studies included. Other selection criteria included whether the methodologies were comparable and fulfilled the following standards: clear and explicit criteria for selection of studies, outcome exactly defined as needed for our study, control for and reporting of heterogeneity, exposure defined in terms of average volume of drinking and exclusion of studies not based on general population. As many of the meta-analyses were based on prior meta-analyses for the same disease conditions and had merely added the newly published literature, this identification was often easy (e.g. Gutjahr et al. 2001 where most of the analyses were based on the previous works of English et al. 1995 and Single et al. 1996). Where meta-analyses used other drinking categories than the ones used here, we interpolated the respective regression coefficients 
Table 2 Alcohol-related disease categories and sources for determining risk relations including alcohol-attributable fractions (AAFs).

\begin{tabular}{|c|c|c|}
\hline Condition & ICD-10 code & Source for meta-analysis or $A A F$ \\
\hline \multicolumn{3}{|l|}{ Malignant neoplasms } \\
\hline Mouth and oropharynx cancers & $\mathrm{C} 00-\mathrm{C} 14$ & Gutjahr et al. (2001) \\
\hline Oesophageal cancer & $\mathrm{C} 15$ & Gutjahr et al. (2001) \\
\hline Liver cancer & $\mathrm{C} 22$ & Gutjahr et al. (2001) \\
\hline Laryngeal cancer & $\mathrm{C} 32$ & Gutjahr et al. (2001) \\
\hline Breast cancer & $\mathrm{C} 50$ & Ridolfo \& Stevenson (2001) \\
\hline Other neoplasms & D00-D48 & Rehm et al. (2004) \\
\hline \multicolumn{3}{|l|}{ Diabetes } \\
\hline Diabetes mellitus & E10-E14 & Gutjahr et al. (2001) \\
\hline \multicolumn{3}{|l|}{ Neuro-psychiatric conditions } \\
\hline Alcoholic psychoses & F10.0, F10.3-F10.9 & $100 \%$ AAF per definition \\
\hline Alcohol abuse & F10.1 & $100 \%$ AAF per definition \\
\hline Alcohol dependence syndrome & F10.2 & $100 \%$ AAF per definition \\
\hline Unipolar major depression & F32-F33 & Rehm et al. (2004) \\
\hline $\begin{array}{l}\text { Degeneration of nervous system due to } \\
\text { alcohol }\end{array}$ & G31.2 & $100 \%$ AAF per definition \\
\hline Epilepsy & G40-G41 & Gutjahr et al. (2001) \\
\hline Alcoholic polyneuropathy & G62.1 & $100 \%$ AAF per definition \\
\hline \multicolumn{3}{|l|}{ Cardiovascular diseases } \\
\hline Hypertensive disease & I10-I15 & Corrao et al. (1999) \\
\hline Ischaemic heart disease & I20-I25 & Corrao et al. (2000); Rehm et al. (2004) \\
\hline Alcoholic cardiomyopathy & $\mathrm{I} 42.6$ & $100 \%$ AAF per definition \\
\hline Cardiac arrhythmias & I47-I49 & Gutjahr et al. (2001) \\
\hline $\begin{array}{l}\text { Heart failure and ill-defined } \\
\text { complications of heart disease }\end{array}$ & $\begin{array}{l}\text { I50-I52, I23, I25.0, } \\
\text { I97.0, I97.1, I98.1 }\end{array}$ & $\begin{array}{l}\text { This is an unspecific category with no } \\
\text { identification of underlying pathology. } \\
\text { Therefore, the relationship between average } \\
\text { volume of consumption cannot be } \\
\text { determined by usual meta-analysis }\end{array}$ \\
\hline Cerebrovascular disease & I60-I69 & \\
\hline Ischaemic stroke & I60-I62 & Reynolds et al. (2003) \\
\hline Haemorrhagic stroke & I63-I66 & Reynolds et al. (2003) \\
\hline Oesophageal varices & I85 & Gutjahr et al. (2001) \\
\hline \multicolumn{3}{|l|}{ Digestive diseases } \\
\hline Alcoholic gastritis & $\mathrm{K} 29.2$ & $100 \%$ AAF per definition \\
\hline Cirrhosis of the liver & K70, K74 & Rehm et al. (2004) \\
\hline Cholelithiasis & K80 & Gutjahr et al. (2001) \\
\hline Acute and chronic pancreatitis & K85, K86.1 & Corrao et al. (1999) \\
\hline Chronic pancreatitis (alcohol-induced) & K86.0 & $100 \%$ AAF per definition \\
\hline \multicolumn{3}{|l|}{ Skin diseases } \\
\hline Psoriasis & L40 & Gutjahr et al. (2001) \\
\hline \multicolumn{3}{|l|}{ Conditions arising during the perinatal period } \\
\hline $\begin{array}{l}\text { Low birth weight: as defined by the } \\
\text { global burden of disease study* }\end{array}$ & P05-P07 & Gutjahr et al. (2001) \\
\hline Fetal alcohol syndrome (dysmorphic) & Q86.0 & $100 \%$ AAF per definition \\
\hline Excess alcohol blood level & $\mathrm{R} 78.0$ & $100 \%$ AAF per definition \\
\hline \multicolumn{3}{|l|}{ Unintentional injuries } \\
\hline Motor vehicle accidents & $\S$ (see footnote) & $\begin{array}{l}\text { Traffic Injury Research Foundation of Canada 2004; } \\
\text { Transport Canada (2004) }\end{array}$ \\
\hline Poisonings & X40-X49 & $\begin{array}{l}\text { Rehm et al. (2004); adjusted to Canada by AAF for } \\
\text { traffic accidents }\end{array}$ \\
\hline Falls & W00-W19 & $\begin{array}{l}\text { Rehm et al. (2004); adjusted to Canada by AAF for } \\
\text { traffic accidents }\end{array}$ \\
\hline Fires & X00-X09 & $\begin{array}{l}\text { Council of Canadian Fire Marshals and Fire } \\
\text { Commissioners (2003) }\end{array}$ \\
\hline
\end{tabular}


Table 2 Cont.

\begin{tabular}{|c|c|c|}
\hline Condition & ICD-10 code & Source for meta-analysis or $A A F$ \\
\hline $\begin{array}{l}\text { Accidental poisoning and exposure to } \\
\text { alcohol }\end{array}$ & $\mathrm{X} 45$ & $100 \%$ AAF per definition \\
\hline Drowning & W65-W74 & $\begin{array}{l}\text { Rehm et al. (2004); adjusted to Canada by AAF for } \\
\text { traffic accidents }\end{array}$ \\
\hline Other unintentional injuries & $\begin{array}{l}\text { †Rest of V \& W20-W64, } \\
\text { W75-W99, X10-X39, } \\
\text { X50-X59, Y40-Y86, } \\
\text { Y88, Y89 }\end{array}$ & $\begin{array}{l}\text { Rehm et al. (2004); adjusted to Canada by AAF for } \\
\text { traffic accidents }\end{array}$ \\
\hline \multicolumn{3}{|l|}{ Intentional injuries } \\
\hline Self-inflicted injuries & $\mathrm{X} 60-\mathrm{X} 84, \mathrm{Y} 87.0$ & $\begin{array}{l}\text { Rehm et al. (2004); adjusted to Canada by AAF for } \\
\text { traffic accidents }\end{array}$ \\
\hline $\begin{array}{l}\text { Intentional self-poisoning by and } \\
\text { exposure to alcohol }\end{array}$ & X65 & $100 \%$ AAF per definition \\
\hline Homicide & X85-Y09, Y87.1 & $\begin{array}{l}\text { Rehm et al. (2004); adjusted to Canada by AAF for } \\
\text { traffic accidents }\end{array}$ \\
\hline Other intentional injuries & Y35 & $\begin{array}{l}\text { Rehm et al. (2004); adjusted to Canada by AAF for } \\
\text { traffic accidents }\end{array}$ \\
\hline $\begin{array}{l}\text { Ethanol and methanol toxicity, undetermined } \\
\text { intent }\end{array}$ & Y15 & $100 \%$ AAF per definition \\
\hline
\end{tabular}

*Relative risk refers to drinking of mothers. §V021-V029, V031-V039, V041-V049, V092, V093, V123-V129, V133-V139, V143-V149, V194-V196, V203-V209, V213-V219, V223-V229, V233-V239, V243-V249,V253-V259, V263-V269, V273V279, V283-V289, V294-V299, V304-V309, V314-V319, V324-V329, V334-V339, V344-V349, V354-V359, V364-V369, V374-V379, V384-V389, V394-V399, V404-V409, V414-V419, V424-V429, V434-V439, V444-V449, V454-V459, V464V469, V474-V479, V484-V489, V494-V499, V504-V509, V514-V519, V524-V529, V534-V539, V544-V549, V554-V559, V564-V569, V574-V579, V584-V589, V594-V599, V604-V609, V614-V619, V624-V629, V634-V639, V644-V649, V654V659, V664-V669, V674-V679, V684-V689, V694-V699, V704-V709, V714-V719, V724-V729, V734-V739, V744-V749, V754-V759, V764-V769, V774-V779, V784-V789, V794-V799, V803-V805, V811, V821, V830-V833, V840-V843, V850V853, V860-V863, V870-V878, V892. 'Rest of V=V-series MINUS §.

to the midpoints of our drinking categories (for definition of drinking categories see Table 1).

The relative risk for each condition was combined with different levels of alcohol consumption for each sex and age group and an attributable fraction was obtained using the following formula (see Walter 1976, 1980), which uses no consumption at all as counterfactual scenario (see Rehm et al. 2001b; Murray et al. 2003; for a discussion of this choice).

$$
A A F=\left[\Sigma_{i=1}^{k} P_{i}\left(R R_{i}-1\right)\right] /\left[\Sigma_{i=0}^{k} P_{i}\left(R R_{\mathrm{i}}-1\right)+1\right]
$$

where $i$ : exposure category with baseline exposure or no alcohol $i=0 ; R R_{\mathrm{i}}$ : relative risk at exposure level $i$ compared to no consumption; $P_{i}$ : prevalence of the ith category of exposure.

The AAFs were then applied to the mortality data to estimate the number of alcohol attributed deaths by age and sex.

For injuries, a different approach had to be adopted because injuries are usually more determined by patterns of excessive per occasion drinking than by average volume of alcohol consumption (see Rehm et al. 2003a, 2004). Thus we looked for injury statistics that would include the blood alcohol level in the event. This was available for the traffic sector, where statistics exist in Canada to explicitly account for blood alcohol concentration (BAC; Traffic Injury Research Foundation of Canada 2004; Transport Canada 2004). To determine causality of alcohol, we used the criterion of BAC larger than $100 \mathrm{mg} / \mathrm{dl}$ (see also Smith et al. 1999). This does exclude all injury with involvement of alcohol at lower levels of BAC. As alcohol influences psychomotor ability at much lower levels (Eckardt et al. 1998), the criterion can be seen as conservative.

For injury categories, where we had no Canadian studies (e.g. falls), we based AAFs on the age and sexspecific values of the America A region of the Comparative Risk Analysis (CRA) of the Global Burden of Disease study (Rehm et al. 2004). The CRA America A region consisted of population weighted estimates for Canada, Cuba and the United States combined, which were heavily based on US studies (especially Smith et al. 1999). These estimates were scaled differences between CRA and Canadian data for motor vehicle accidents: if, for example, the Canadian prevalence rates were $8 \%$ lower for motor vehicle accidents in a sex-age category, this ratio (0.92) was transferred to decrease the AAF for other injury types without specific Canadian data; if they 
were higher, the AAFs for other injury types were increased accordingly.

\section{Mortality data}

Mortality data in Canada for the year 2001, with the underlying cause coded according to the International Classification of Diseases version 10 (ICD-10), were obtained from Statistics Canada. Table 2 gives an overview of the disease conditions extracted by sex and age groups; 2001 was selected because it was the last year available.

\section{Potential years of life lost}

Potential years of life lost (PYLL) is an indicator of premature mortality. People dying due to alcohol consumption would have lived longer if they had not drunk alcohol. The average extra time such individuals would have lived is known as the residual life expectancy. For example, if a male died of alcoholic liver cirrhosis at age 50, in Canada he would have a residual life expectancy of 28.4 years (WHO Statistical Information System 2000). The sum of these extra times for all people dying from alcohol consumption is known as PYLL due to alcohol. PYLL for each sex-age group category can be estimated from the observed mean age at death in the age interval and the standard life expectancies tables at the exact ages defining the age interval through interpolation. The standard life expectancies table for Canada mortality in 2000 is available from the World Health Organization (WHO) website (http://www.who.int/ evidence). In calculating the mean ages within the intervals, the rules specified by the Global Burden of Disease study have been followed (Mathers et al. 2001). PYLL due to death in Canada has been calculated for each age group (0-14, 15-29, 30-44, 45-59, 60-69, 70-79 and $80+$ years) by multiplying the number of deaths by the interpolated life expectancy for the observed mean age at death in the interval. Mean age for the $80+$ age groups for men (84 years) and women ( 85 years) were calculated from the life expectancy table. The upper age limit of 76.0 years for males and 81.5 years for females was used to approximate the life expectancy of Canadians for both sexes at birth. PYLL were calculated per population of 100000 .

\section{Sensitivity analyses}

Different measures of alcohol exposure were used as a basis to estimate alcohol-attributable mortality and PYLL:

- the 7-day-consumption protocol;

- the usual QF measure, as indicated by the respondents;

- a smoothed QF, where abrupt changes in prevalence of different drinking level categories between adjacent age groups were smoothed on the basis of the overall linear age distribution of volume of drinking; and

- a smoothed QF adjusted in a way that the overall volume in Canada corresponded to the per capita consumption, including unrecorded consumption.

As the last measure corresponded to the best estimate of overall consumption in Canada, it was considered the main measure of alcohol exposure.

\section{RESULTS}

Table 1 gives an overview of the estimated volume of alcohol exposure in Canada by sex and age group. As expected, men consumed on average more than women, and alcohol consumption decreased with age.

Table 3 provides the estimates of alcohol-attributable deaths and deaths prevented by alcohol consumption. Overall, in Canada for 2001, 3892 alcohol-attributable deaths were estimated accounting for 3313 deaths among men and 579 among women. Please note that these numbers were derived by multiplying AAFs with number of deaths for each category, thereby producing numbers with decimals. As a result, there may be rounding errors after collapsing numbers over different categories.

The 3892 alcohol-attributable deaths constituted $1.8 \%$ of all Canadian deaths. These were net figures, i.e. they included estimates of deaths prevented by alcohol. Overall, there were 7597 deaths attributable to alcohol and 3705 deaths prevented by alcohol, calculated using the same epidemiological procedure described above. Most of the estimated deaths prevented by alcohol were from IHD (3010 deaths). Overall, most of these statistically calculated 'prevented' deaths occur after age $70(78.7 \%$ of all prevented deaths). There is some doubt as to whether the metaanalytically derived AAFs both for deaths caused and for preventive deaths really apply to this age group, as relative risks tend to converge to 1 with age. Thus, we additionally present the figures of alcohol-attributable mortality for the age-group under 70 years. In this age group, 4010 of all deaths in Canada 2001 were attributed to alcohol, accounting for 3132 men and 877 women. This represented $6.0 \%$ of all Canadian deaths in this age-group.

Among deaths caused by alcohol, the three biggest contributors were unintentional injuries, malignant neoplasms and digestive diseases (see Table 3). With respect to single disease categories, cirrhosis of the liver (1203 deaths, 854 males; 349 females), motor vehicle accidents (801 deaths, 662 males; 138 females), suicides/selfinflicted injuries (619 deaths, 507 males; 113 females), oesophageal cancer (467 deaths, 383 males; 84 females) and cardiac arrhythmias (412 deaths, 218 males; 194 


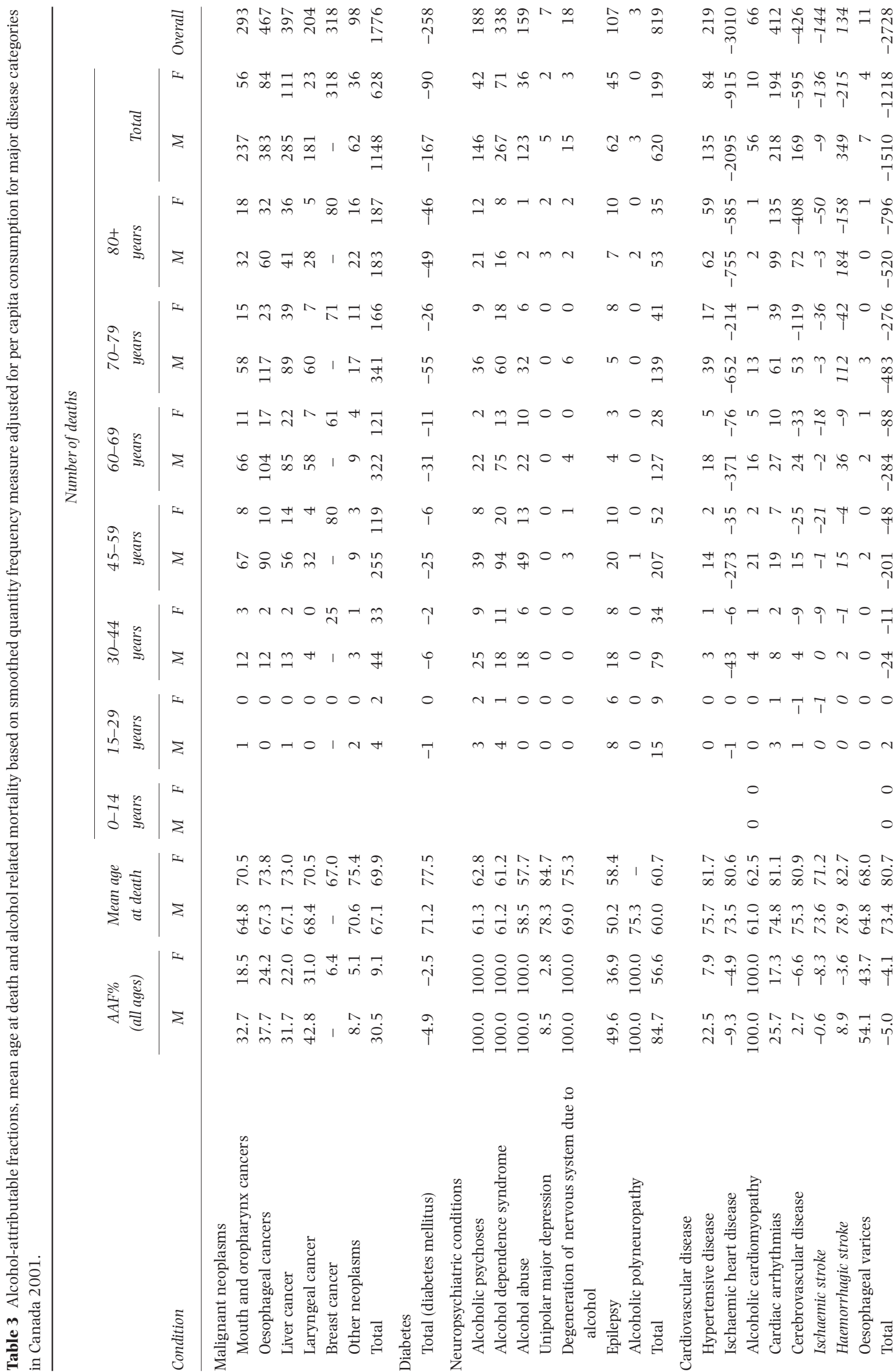




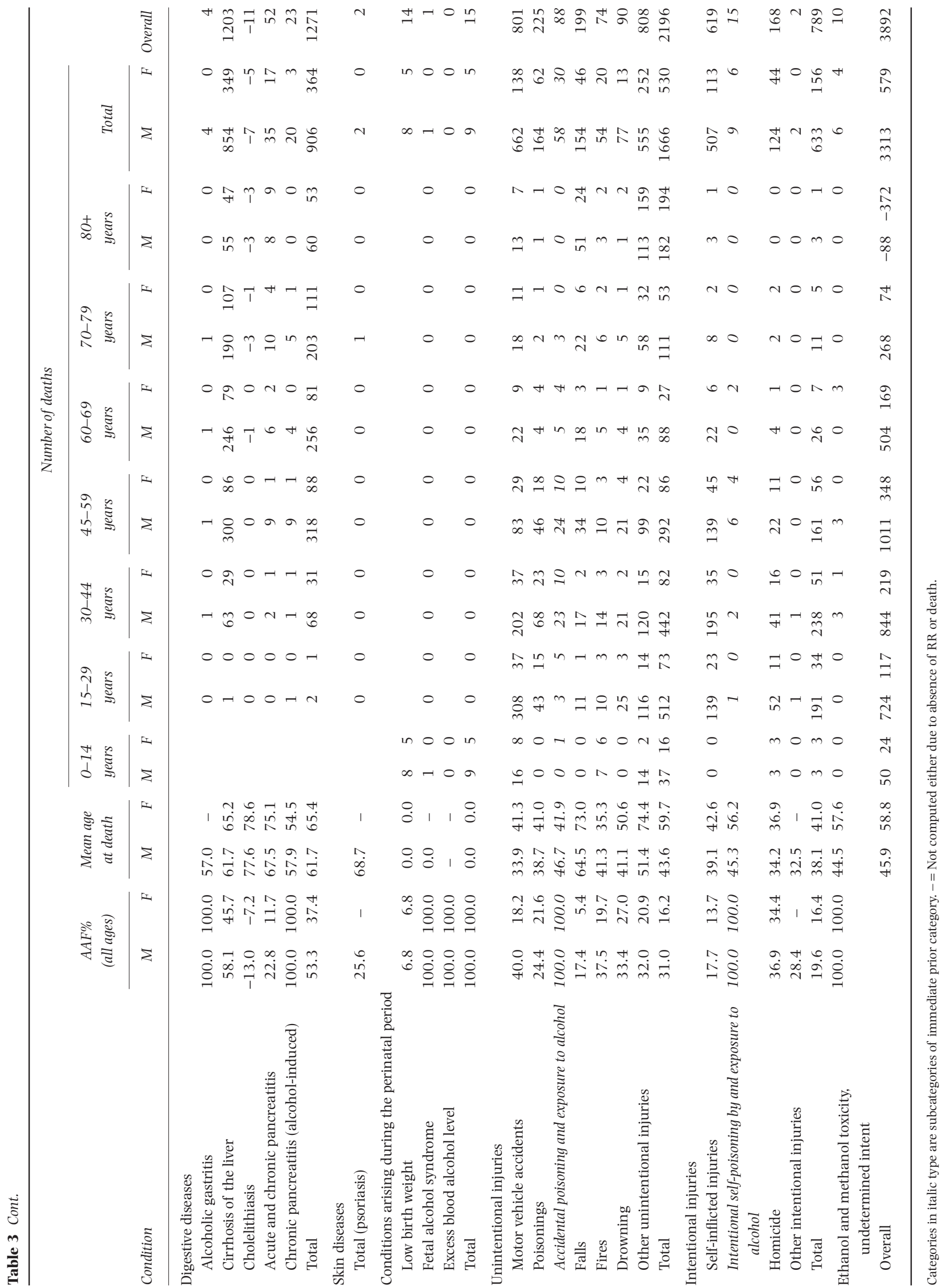


females) constituted the largest alcohol-attributable categories.

Overall, alcohol affected more men than women: in men $3.0 \%$ of the deaths were alcohol-attributable and in women the figure was $0.5 \%$ (in the age group under 70 : $7.6 \%$ in men; $3.5 \%$ in women).

With respect to age, the overall average age for an alcohol-attributable death was 45.9 years for men and 58.8 years for women. There were notable differences between disease categories. For cardiac arrhythmias, the average age for an alcohol-attributable death was

Table 4 Potential years of life lost (PYLL) attributable to alcohol in Canada 2001 by age and sex-main scenario.

\begin{tabular}{lcrr}
\hline Gender & $\begin{array}{l}\text { Age group } \\
\text { (years) }\end{array}$ & $\begin{array}{l}\text { Alcohol-attributable } \\
\text { death all causes }\end{array}$ & \multicolumn{1}{l}{ PYLL } \\
\hline Men & $0-14$ & 50 & 3418.1 \\
& $15-29$ & 724 & 39349.4 \\
& $30-44$ & 844 & 33760.0 \\
& $45-59$ & 1011 & 26437.7 \\
$60-69$ & 504 & 8038.8 \\
& $70-79$ & 268 & 2559.4 \\
& $80+$ & -88 & -484.0 \\
& & & 113079.3
\end{tabular}

Alcohol-attributable years of life lost per 100000 men $=769$

\begin{tabular}{|c|c|c|c|}
\hline \multirow[t]{7}{*}{ Women } & $0-14$ & 24 & 1770.8 \\
\hline & $15-29$ & 117 & 6970.9 \\
\hline & $30-44$ & 219 & 9828.7 \\
\hline & $45-59$ & 348 & 10669.7 \\
\hline & $60-69$ & 169 & 3337.8 \\
\hline & $70-79$ & 74 & 903.5 \\
\hline & $80+$ & -372 & -2418.0 \\
\hline
\end{tabular}

Alcohol-attributable years of life lost per 100000 women $=203$

Total PYLL

144143
74.8 years for men and 81.1 years for women. Alcoholattributable deaths due to motor vehicle accidents occurred at the average age of 33.9 years for men and 41.3 years for women. For the category of alcoholprevented deaths in general, the mean age was 74.4 years among men and 80.7 years among women.

In 2001, the PYLL rate for Canada for deaths due to alcohol was 769 per 100000 for men and 203 per 100000 for women aged $0-80+($ Table 4$)$. That is, for every 100000 people in the population, there was a potential loss of 769 years of life among men and 203 years of life among women as a result of premature death due to alcohol. A high PYLL rate for men was observed, indicating higher levels of premature mortality among men compared to women.

Although the estimates of alcohol exposure varied widely, i.e. by a factor of three between some survey measures and per capita consumption, the estimates for alcohol-attributable mortality did not vary by such a large degree (see Table 5): the lowest estimate was only $22.8 \%$ lower than the highest estimate.

Similarly, the PYLL rate per 100000 population varied much less compared to the variation in exposure. For instance, between the main scenario (see Table 4) and a scenario based on usual quantity-frequency, the differences were as follows: the rate of alcohol-attributable years of life lost per 100000 men decreased from 769 to $698(-9.2 \%)$ and the respective rate for women decreased from 203 to 174 (-14.3\%; details of the calculation available from the authors).

There are three main reasons for the relatively small variation in overall deaths or PYLL. First, only part of the alcohol-attributable mortality was based on survey estimates (see Methods above). The rest was derived using direct estimation from statistics. Secondly, as alcohol has protective as well as detrimental effects, and as the esti-

Table 5 Sensitivity analysis on resulting burden under different exposure scenarios.

\begin{tabular}{|c|c|c|c|c|c|c|c|c|c|}
\hline $\begin{array}{l}\text { Exposure } \\
\text { scenarios }\end{array}$ & Gender & $\begin{array}{l}\text { Malignant } \\
\text { neoplasms }\end{array}$ & Diabetes & $\begin{array}{l}\text { Neuro- } \\
\text { psychiatric } \\
\text { conditions }\end{array}$ & $\begin{array}{l}\text { Cardiovascular } \\
\text { diseases }\end{array}$ & $\begin{array}{l}\text { Digestive } \\
\text { diseases }\end{array}$ & $\begin{array}{l}\text { Skin } \\
\text { diseases }\end{array}$ & $\begin{array}{l}\text { Conditions } \\
\text { arising during } \\
\text { perinatal period }\end{array}$ & $\begin{array}{l}\text { Total } \\
\text { net } \\
\text { deaths } \dagger\end{array}$ \\
\hline \multirow[t]{2}{*}{ S1 usual QF } & Male & 828 & -68 & 592 & -1533 & 580 & 1 & 4 & 2709 \\
\hline & Female & 389 & -61 & 182 & -860 & 209 & 0 & 2 & 551 \\
\hline \multirow[t]{2}{*}{ S2 7-day-recall } & Male & 727 & -47 & 583 & -1293 & 469 & 1 & 4 & 2750 \\
\hline & Female & 365 & -56 & 181 & -797 & 182 & 0 & 2 & 568 \\
\hline \multirow{2}{*}{$\begin{array}{c}\text { S3 smoothed } \\
\text { usual QF }\end{array}$} & Male & 865 & -70 & 596 & -1583 & 591 & 1 & 4 & 2710 \\
\hline & Female & 426 & -71 & 185 & -1149 & 210 & 0 & 2 & 293 \\
\hline \multirow{2}{*}{$\begin{array}{l}\text { S4 smoothed } \\
\text { adjusted QF }\end{array}$} & Male & 1148 & -167 & 620 & -1510 & 906 & 2 & 9 & 3313 \\
\hline & Female & 628 & -90 & 199 & -1218 & 364 & 0 & 5 & 579 \\
\hline
\end{tabular}

${ }^{\dagger}$ Note that the total of net deaths is not the sum of the chronic conditions only, but the sum of these conditions plus the deaths due to injury (see Table 3 for numbers). As the latter were estimated directly from statistics and independently of exposure, they remain constant for all scenarios. S1= Alcoholattributable fractions (AAF) based on usual quantity frequency $(\mathrm{QF})$ measure. S2 = AAF based on 7-day-recall. S3 = AAF based on smoothed usual $\mathrm{QF}$ measure. S4 = AAF based on smoothed $\mathrm{QF}$ measure adjusted for per capita consumption. 
mation of these effects depends on certain patterns of drinking (Rehm et al. 2003a), the effects of changes in volume of alcohol consumption on mortality are not linear, but depend on the distribution of drinking with respect to different volume categories, sex and age. Thirdly, a number of disease conditions are wholly attributable to alcohol (e.g. alcohol dependence), and thus their mortality is estimated independently of prevalence of alcohol consumption.

\section{DISCUSSION}

Alcohol consumption has substantial consequences for public health. Regardless of how alcohol intake is measured, it causes substantial mortality and years of life lost in Canada. Before we address potential ways to reduce alcohol-related harm, we would like to outline some of the limitations and potential problems of the present study. Exposure measurement is one of the biggest challenges in alcohol epidemiology. While we have relatively good per capita estimates (Rehm et al. 2003d), at least in countries such as Canada with relatively small proportions of unrecorded consumption, the distribution by sex and age, as derived from surveys, is problematic. The main problem is that surveys account for $50 \%$ or less of sales/production figures. That fact has been known for some time (e.g. Midanik 1988), but has not been addressed adequately with respect to epidemiology. The underlying measures of exposure also explain some of the variation between studies, where overall little or no net loss of mortality could be measured (e.g. Single et al. 1996; Britton et al. 2003; White et al. 2004) compared to studies where the net mortality is considerable (such as Rehm et al. 2004, or the present study). In the studies with little or no net loss of mortality, level of alcohol consumption was derived from surveys resulting in considerable underestimation of true consumption. There are other differences that explain the variations in study results, most importantly the number of disease categories included and the estimation of injury deaths (based on country-specific statistics or not). In comparison with the earlier Canadian study of Single and colleagues (Single et al. 1996), three other changes are important: the proportion of deaths in Canada due to IHD and cerebrovascular diseases decreased, and the relative risk estimates for the latter disease category changed considerably (compare the relative risks provided by English et al. 1995 to those from Reynolds et al. 2003). Thus, the estimated overall protective effect of alcohol consumption decreased.

A second problem concerns the estimation of risk relations for chronic disease, which still mainly do not take into account patterns of drinking. This may be less relevant for malignant neoplasm but certainly there is good evidence on alcohol and IHD to demonstrate that drinking pattern plays a crucial role (Puddey et al. 1999; Rehm et al. 2003c). There are also good examples of how this is relevant for public health. For example, in a representative follow-up study in the United States, a protective effect of average moderate consumption could be found in whites but not in African Americans (Sempos et al. 2002; for a Canadian example on the relevance of patterns see Murray et al. 2002). Thus, the burden estimates for all diseases where patterns are important can only be considered preliminary until we have a better understanding of the patterns of consumption in a population and the resulting disease outcomes. This point is especially important for the area of cardiovascular disease outcomes, where patterns of drinking may change the result from beneficial to detrimental effects of alcohol (Gmel et al. 2003b).

Thirdly, as already indicated above, the age specificity of relative risks between exposure and outcomes should be taken into consideration. For example, the relative risk of alcohol for IHD declines with age (Abrams et al. 1995), but in most estimations of alcohol-related harm, including this paper, the same relative risks have been used for all age groups. This leads to an overestimation of deaths caused and prevented by alcohol in older age groups, which is especially relevant for IHD deaths prevented, where we almost certainly obtain a significant overestimate using the current methodology. In fact, the majority of the beneficial effects of alcohol would disappear if agespecific relative risk estimates were used.

While such details are certainly important in improving future estimations of burden, they should not detract from the main result in this study. Under all assumptions, alcohol consumption in Canada resulted in a considerable burden of mortality and disease. In appraising this burden, it should be mentioned that disease burden is only part of the overall alcohol-related burden, and is actually considerably smaller than social harm in some regions (Room et al. 2003). Thus, in making policy decisions, consideration should be given to all consequences of alcohol, including social harm. In shaping policies, one must also look at the whole picture of the alcohol consumption culture and not concentrate only on excessive drinking (Centers for Disease Control \& Prevention 2004), as excessive drinking and moderate drinking, with their different effects on health, are often intertwined, i.e. effects on one style may have unwanted effects on the other.

The burden related to alcohol in Canada is an unnecessary one. A large portion of this burden could be reduced considerably in a short period of time (WHO 2002; Chisholm et al. 2004) if known effective policies were implemented. In Canada, policies such as taxation, improvement of drinking driving countermeasures and 
specific measures to reduce aggression and violence seem to be the most promising policies, given the epidemiological profile (Babor et al. 2003; Chisholm et al. 2004; Room et al. 2005). Such policies have proved their effectiveness in many jurisdictions and they could show effects almost immediately (Babor et al. 2003; Chisholm et al. 2004; Room et al. 2005).

\section{Acknowledgements}

This contribution was in part enabled by funding for the Second Canadian Study on Social Costs of Substance Abuse from various sources, under the umbrella of the Canadian Centre on Substance Abuse. We would like to thank Dolly Baliunas, Marta Manczuk, Urszula Mitura, Ben Taylor, Witold Zatonski and three anonymous reviewers for helpful comments on earlier versions of this paper.

\section{References}

Abrams, J., Vela, B. S., Coultas, D. B., Samaan, S. A., Malhotra, D. \& Roche, R. J. (1995) Coronary risk factors and their modification: lipids, smoking, hypertension, estrogen and the elderly. Current Problems in Cardiology, 20, 533-610.

Ashley, M. J., Rehm, J., Bondy, S., Single, E. \& Rankin, J. (2000) Beyond ischaemic heart disease: are there other health benefits from drinking alcohol? Contemporary Drug Problems, 27. 735-777.

Babor, T., Caetano, R., Casswell, S., Edwards, G., Giesbrecht, N., Graham, K. et al. (2003) Alcohol: No Ordinary CommodityResearch and Public Policy. Oxford and London: Oxford University Press.

Baum-Baicker, C. (1985) The health benefits of moderate alcohol consumption: a review of the literature. Drug and Alcohol Dependence, 15, 207-227.

Britton, A., Nolte, E., White, I. R., Grønbæk, M., Powles, J., Cavallo, F. et al. (2003) A comparison of the alcohol-attributable mortality in four European countries. European Journal of Epidemiology, 18, 643-651.

Canadian Centre on Substance Abuse (2004) Canadian Addiction Survey 2004: Microdata eGuide. Ottawa: Canadian Centre on Substance Abuse.

Castaneda, R., Sussman, N., Levy O’Malley, M. \& Westreich, L. (1998) A review of the effects of moderate alcohol intake on psychiatric and sleep disorders. In: Galanter, M., ed. Recent Developments in Alcoholism: the Consequences of Alcoholism, pp. 197-226. New York: Plenum Press.

Castaneda, R., Sussman, N., Westreich, L. \& Levy O'Malley, M. (1996) A review of the effects of moderate alcohol intake on the treatment of anxiety and mood disorders. Journal of Clinical Psychiatry, 57, 207-212.

Centers for Disease Control and Prevention (2004) Alcoholattributable deaths and years of potential life lost. United States, 2001. Morbidity and Mortality Weekly Report, 53, 866870

Chick, J. (1998) Alcohol, health and the heart: implications for clinicians. Alcohol and Alcoholism, 33, 576-591.

Chick, J. (1999) Can light or moderate drinking benefit mental health? European Addiction Research, 5, 74-81.

Chisholm, D., Rehm, J., van Ommeren, M. \& Monteiro, M. (2004) Reducing the global burden of hazardous alcohol use: a comparative cost-effectiveness analysis. Journal of Studies on Alcohol, 65, 782-793.

Corrao, G., Bagnardi, V., Zambon, A. \& Arico, S. (1999) Exploring the dose-response relationship between alcohol consumption and the risk of several alcohol-related conditions: a metaanalysis. Addiction, 94, 1551-1573.

Corrao, G., Rubbiati, L., Bagnardi, V., Zambon, A. \& Poikolainen, K. (2000) Alcohol and coronary heart disease: a metaanalysis. Addiction, 95, 1505-1523.

Council of Canadian Fire Marshals and Fire Commissioners. (2003) Fire Losses in Canada. Annual report 2000. Ottawa, Canada: Council of Canadian Fire Marshals and Fire Commissioners.

Doll, R., Peto, R., Hall, E., Wheatley, K. \& Gray, R. (1994) Mortality in relation to consumption of alcohol: 13 years' observations on male British doctors. BMJ, 309, 911-918.

Eckardt, M. J., File, S. E., Gessa, G. L., Grant, K. A., Guerri, C., Hoffman, P. L. et al. (1998) Effects of moderate alcohol consumption on the central nervous system. Alcoholism: Clinical and Experimental Research, 22, 998-1040.

English, D. R., Holman, C. D. J., Milne, E., Winter, M. J., Hulse, G. K., Codde, G. et al. (1995) The Quantification of Drug Caused Morbidity and Mortality in Australia 1995. Canberra, Australia: Commonwealth Department of Human Services and Health.

Gmel, G., Gutjahr, E. \& Rehm, J. (2003a) How stable is the risk curve between alcohol and all-cause mortality and what factors influence the shape? A precision-weighted hierarchical meta-analysis. European Journal of Epidemiology, 18, 631-642.

Gmel, G. \& Rehm, J. (2004) Measuring alcohol consumption. Contemporary Drug Problems, 31, 467-540.

Gmel, G., Rehm, J. \& Frick, U. (2003b) Trinkmuster, Pro-KopfKonsum von Alkohol und koronare Mortalität [Patterns of drinking, per capita consumption of alcohol and coronary mortality]. Sucht, 49, 95-104.

Gutjahr, E., Gmel, G. \& Rehm, J. (2001) Relation between average alcohol consumption and disease: an overview. European Addiction Research, 7, 117-127.

Hauge, R. \& Irgens-Jensen, O. (1990) The experience of positive consequences of drinking in four Scandinavian countries. British Journal of Addiction, 85, 645-653.

Klatsky, A. L. (1994) Epidemiology of coronary heart disease influence of alcohol. Alcoholism: Clinical and Experimental Research, 18, 88-96.

Mathers, C. D., Vos, A., Lopez, A. D., Salomon, J. \& Ezzati, M., eds (2001) National Burden of Disease Studies: a Practical Guide. Global Program on Evidence for Health Policy, 2nd edn. Geneva: World Health Organization.

Midanik, L. (1988) Validity of self-reported alcohol use: a literature review and assessment. British Journal of Addiction, 83, $1019-1029$

Murray, R. P., Connett, J. E., Tyas, S. L., Bond, R., Ekuma, O., Silversides, C. K. et al. (2002) Alcohol volume, drinking pattern, and cardiovascular disease morbidity and mortality: is there a U-shaped function? American Journal of Epidemiology, 155 242-248

Murray, C. J. L., Ezzati, M., Lopez, A. D., Rodgers, A. \& VanderHoorn, S. (2003) Comparative quantification of health risks conceptual framework and methodological issues. Population Health Metrics, 1, 1-20. Available at: http:// www.pophealthmetrics.com/content/1/1/1 (accessed 15 July, 2005)

National Health and Medical Research Council, Australia (1992) Is There a Safe Level of Daily Consumption of Alcohol for Men and Women? Canberra: AGPS. 
Pohorecky, L. A. (1991) Stress and alcohol interaction: an update of human research. Alcoholism: Clinical and Experimental Research, 15, 438-459.

Puddey, I. B., Rakic, V., Dimmitt, S. B. \& Beilin, L. J. (1999) Influence of pattern of drinking on cardiovascular disease and cardiovascular risk factors-a review. Addiction, 94, 649663.

Rehm, J. \& Bondy, S. (1998) Alcohol and all-cause mortality: an overview. In: Chadwick, D. J. \& Goode, J. A., eds. Alcohol and Cardiovascular Diseases, pp. 223-232. Chichester: Wiley.

Rehm, J., Gmel, G., Sempos, C. T. \& Trevisan, M. (2003b) Alcohol-attributable mortality and morbidity. Alcohol Research and Health, 27, 39-51.

Rehm, J., Greenfield, T. K., Walsh, G., Xie, X., Robson, L. \& Single, E. (1999) Assessment methods for alcohol consumption, prevalence of high risk drinking and harm: a sensitivity analysis. International Journal of Epidemiology, 28, 219-224.

Rehm, J., Gutjahr, E. \& Gmel, G. (2001a) Alcohol and all-cause mortality: a pooled analysis. Contemporary Drug Problems, 28, 337-361.

Rehm, J., Monteiro, M., Room, R., Gmel, G., Jernigan, D., Frick, U. et al. (2001b) Steps towards constructing a global comparative risk analysis for alcohol consumption: determining indicators and empirical weights for patterns of drinking, deciding about theoretical minimum, and dealing with different consequences. European Addiction Research, 7, 138-147.

Rehm, J., Rehn, N., Room, R., Monteiro, M., Gmel, G., Jernigan, D. et al. (2003d) The global distribution of average volume of alcohol consumption and patterns of drinking. European Addiction Research, 9, 147-156.

Rehm, J., Room, R., Graham, K., Monteiro, M., Gmel, G. \& Sempos, C. T. (2003a) The relationship of average volume of alcohol consumption and patterns of drinking to burden of disease-an overview. Addiction, 98, 1209-1228.

Rehm, J., Room, R., Monteiro, M., Gmel, G., Graham, K., Rehn, N. et al. (2004) Alcohol use. In: Ezzati, M., Lopez, A. D., Rodgers, A. \& Murray, C. J. L., eds. Comparative Quantification of Health Risks Global and Regional Burden of Disease Attributable to Selected Major Risk Factors, pp. 959-1109. Geneva: World Health Organization.

Rehm, J., Sempos, C. T. \& Trevisan, M. (2003c) Average volume of alcohol consumption, patterns of drinking and risk of coronary heart disease-a review. Journal of Cardiovascular Risk, $10,15-20$.

Reynolds, K., Lewis, B., Nolen, J. D., Kinney, G. L., Sathya, B. \& He, J. (2003) Alcohol consumption and risk of stroke: a metaanalysis. JAMA, 289, 579-588.

Ridolfo, B. \& Stevenson, C. (2001) The Quantification of DrugCaused Mortality and Morbidity in Australia 1998. Canberra, Australia: Australian Institute of Health and Welfare.
Room, R., Babor, T. \& Rehm, J. (2005) Alcohol and public health: a review. Lancet, 365, 519-530.

Room, R., Graham, K., Rehm, J., Jernigan, D. \& Monteiro, M. (2003) Drinking and its burden in a global perspective: policy considerations and options. European Addiction Research, 9, 165-175.

Schultz, J., Rice, D. \& Parker, D. (1990) Alcohol-attributable mortality and years of potential life lost-United States, 1987. Morbidity and Mortality Weekly Report, 39, 173-178.

Schultz, J. M., Rice, D. P., Parker, D. L., Goodman, R. A., Stroh, G. \& Chalmers, N. (1991) Quantifying the disease impact of alcohol with ARDI software. Public Health Reports, 106, 443-450.

Sempos, C. T., Rehm, J., Crespo, C. \& Trevisan, M. (2002) No protective effect of alcohol consumption on coronary heart disease (CHD) in African Americans: average volume of drinking over the life course and CHD morbidity and mortality in a U.S. national cohort. Contemporary Drug Problems, 29, 805-820.

Single, E., Rehm, J., Robson, L. \& Van Truong, M. (2000) The relative risks and aetiologic fractions of different causes of death and disease attributable to alcohol, tobacco and illicit drug use in Canada. Canadian Medical Association Journal, 162, 16691675.

Single, E., Robson, L., Xie, X. \& Rehm, J. (1996) The Costs of Substance Abuse in Canada. Ottawa: Canadian Centre on Substance Abuse.

Smith, G. S., Branas, C. C. \& Miller, T. R. (1999) Fatal nontraffic injuries involving alcohol: a metaanalysis. Annals of Emergency Medicine, 33, 659-668.

Traffic Injury Research Foundation of Canada (2004) AlcoholCrash Problem in Canada: 2002. Ottawa: Canadian Council for Motor Transport Administrators Standing Committee on Road Safety Research and Policies and Transport Canada.

Transport Canada (2004) Road Safety in Canada-2001. Available at: http://www.tc.gc.ca/roadsafety/tp/tp13951/2001/ menu.htm (accessed 15 September, 2004).

Walter, S. D. (1976) The estimation and interpretation of attributable risk in health research. Biometrics, 32, 829-849.

Walter, S. D. (1980) Prevention of multifactorial disease. American Journal of Epidemiology, 112, 409-416.

White, I. R., Altmann, D. R. \& Nanchahal, K. (2004) Mortality in England and Wales attributable to any drinking, drinking above sensible limits and drinking above lowest-risk level. Addiction, 99, 749-756.

World Health Organization (WHO) (2002) World Health Report 2002: Reducing Risks, Promoting Healthy Life. Geneva: World Health Organization.

World Health Organization (WHO) Statistical Information System. (2000) Life tables for 191 countries for 2000: data, methods, results. Discussion Paper no. 40. Geneva: World Health Organization. 